\title{
Common Mutations in the Fibroblast Growth Factor Receptor 3 (FGFR 3) Gene Account for Achondroplasia, Hypochondroplasia and Thanatophoric Dwarfism
}

\author{
J. Bonaventure, F. Rousseau, L. Legeai-Mallet, M. Le Merrer, A. Munnich and P. Maroteaux \\ Service de Génétique et Unité de Recherches sur les Handicaps Génétiques de l'Enfant, INSERM U 393, \\ Hôpital Necker, Paris, France
}

\begin{abstract}
The mapping of the achondroplasia locus to the short arm of chromosome 4 and the subsequent identification of a recurrent missense mutation (G380R) in the fibroblast growth factor receptor 3 (FGFR-3) gene, has been followed by the detection of common FGFR-3 mutations in two clinically related disorders: thanatophoric dwarfism (types I and II) and hypochondroplasia. The relative clinical homogeneity of achondroplasia was substantiated by demonstration of its genetic homogeneity as more than $98 \%$ of all patients hitherto reported, exhibited mutations in the transmembrane receptor domain. Although most of hypochondroplasia cases were accounted for by a recurrent missense substitution (N540K) in the first tyrosine kinase (TK 1) domain of the receptor, a significant proportion $(40 \%)$ of our patients did not harbor the N540K mutation and three hypochondroplasia families were not linked to the FGFR-3 locus, thus supporting clinical heterogeneity of this disease. In thanatophoric dwarfism (TD), a recurrent FGFR-3 mutation located in the second tyrosine kinase (TK 2) domain of the receptor has been detected in $100 \%$ of TD II cases, while 7 distinct mutations in three different protein domains were identified in 25 out of 26 TD I patients, suggesting that TD, like achondroplasia is a genetically homogenous skeletal disorder.
\end{abstract}

Key words: FGFR-3, achondroplasia, hypochondroplasia, thanatophoric dysplasia, tyrosine-kinase

\section{Introduction}

More than 10 years ago, J. Spranger proposed to delineate chondrodysplasia phenotype 'families' of differing severity on the basis of common clinical and radiological features (1). One of these families (achondroplasia family) is char-

Correspondence: Dr. J. Bonaventure, Service de Génétique et Unité de Recherches sur les Handicaps Génétiques de l'Enfant, INSERM U393, Tour Lavoisier, Hôpital Necker 149, rue de Sèvres 75743 Paris cedex 15, France acterized by a continuum of severity ranging from mild forms of dwarfism (hypochondroplasia) to lethal neonatal dwarfisms (thanatophoric dysplasia). It was then hypothesized that mutations in a common gene could account for these conditions. This assertion was supported by several observations: first, inter and intra familial variability does exist in hypochondroplasia with some forms resembling achondroplasia; second, a proband born to a parent with achondroplasia and a parent with hypochondroplasia had more severe skeletal abnormalities than heterozygous achondroplasia; third, homozygous achondropla- 
sia patients born to heterozygous parents usually died at birth or soon after, presenting radiological features that closely resemble TD.

In 1994, a gene for achondroplasia was mapped to chromosome 4p16 $(2,3)$. Among the five genes that had been ascribed to this $2.5 \mathrm{Mb}$ region, the FGFR-3 gene which is expressed in cartilage (4) appeared as the best candidate. This assertion was rapidly substantiated by detection of a recurrent FGFR-3 mutation in 39/39 achondroplasia patients $(5,6)$.

Consistent with the relative clinical homogeneity of achondroplasia, was the demonstration that more than $97 \%$ of all patients had the G380R substitution in the transmembrane receptor domain, thus indicating that guanosine 1138 of the FGFR-3 gene, might represent the most mutable nucleotide in the genome (7).

Not unexpectedly, FGFR-3 mutations were detected in both types of $\operatorname{TD}(8,9)$ either in the extracellular or intracellular domains of the receptor.

Finally, a recurrent missense mutation located in the TK 1 receptor domain was recently shown to account for more than $60 \%$ of hypochondroplasia cases thus confirming that achondroplasia and hypochondroplasia are allelic disorders $(10,11)$.

Identification of FGFR-3 mutations in additional achondroplasia patients, in 23 familial or sporadic cases of hypochondroplasia and in a series of 25 cases with TD I is reported here. Radiological features of TD1 patients harboring mutations in three distinct domains of the receptor are presented.

\section{Materials and Methods}

\section{Patients and cultured cells}

Blood samples were collected from achondroplasia and hypochondroplasia patients. Skin biopsies and cartilage samples from aborted TD foetuses were obtained under familial agreement after interruption of pregnancy. Genomic DNA
Table 1 Primers used for PCR amplifications

Exon 7: first step:
5' AACCCCACTCCCTCCATCTC 3'
5' CAAGGAGAGAACCTCTAGCT 3'
second step:
5' CTGAGCGTCATCTGCCCC 3'
5' CGCCTGCAGGATGGGCCG 3'

Exon 10

5' GCCGAGGAGGAGCTGGTGGAGGCT 3'

5' CTTGAGCGGGAAGCGGAGATCTTG 3'

Exon 11
5' GCCACTGACAAGGACCTGTCGG 3'
5' CCCTTGGCCGCGTACTCCACCAG $3^{\prime}$
Exon 19
5' CCTGTCGGCGCCTTTCGAGCAGTAC 3'
5' CACCAGCAGCAGGGTGGGCTGCTAG 3'

was extracted according to standard procedures from white blood cells, dermal fibroblast cultures or frozen tissues. For histological studies, decalcified sections were stained with hematoxylin, eosin, safran.

\section{PCR amplification and SSCP analysis}

Exon numbering was based on the genomic organization of the mouse Fgfr-3 gene (12). Exons 10,11 and 19 were amplified by using primers presented in Table 1. Polymerase chain reaction with annealing temperature of $62^{\circ} \mathrm{C}$ for 35 cycles in the presence of $5 \%$ DMSO generated PCR fragments of $186 \mathrm{bp}, 180 \mathrm{bp}$ and $226 \mathrm{bp}$. Amplification of exon 7 which encodes the linker region between Ig II and III loops was achieved by using a two-steps protocol. Primers are presented in Table 1 and PCR conditions were similar to those described by Tavormina et al. (13) which resulted in a 55bp DNA fragment. For SSCP analysis, PCR was carried out in the presence of [33P] dCTP $(0.1 \mu \mathrm{l} / 50 \mu \mathrm{l})$. Labelled PCR products were denatured then loaded on hydrophobic MDE gels as recommended by the manufacturer (Bioprobe systems) and run in $0.6 \mathrm{TBE}$ buffer at $250 \mathrm{~V}$ for $16 \mathrm{~h}$. Gels were dried and autoradiographed. 


\section{DNA sequencing and restriction enzyme analysis}

PCR products were purified on Nu-Sieve agarose gels and sequenced using the fluorescent dideoxy-terminator method on an automated DNA sequencer (Applied Biosystems). To detect the $\mathrm{C} / \mathrm{T}$ transition at nucleotide 742 in exon 7 , a $55 \mathrm{bp}$ fragment was digested with $5 \mathrm{U}$ of Bsi HKAI (New England Biolabs) as recommended by the manufacturer, then run on a $15 \%$ polyacrylamide gel and stained with ethidium bromide. Cleavage into two fragments of 26 and $29 \mathrm{bp}$ was observed when the mutation was present. The $\mathrm{C} / \mathrm{G}$ transversion at nucleotide 746 created a new BsoFI site which cleaved the 55 bp products into two fragments of 26 and $29 \mathrm{bp}$. The stop codon mutations at nucleotide 2416 (T/G and T/A) destroyed an MaeII restriction site while the $\mathrm{A} / \mathrm{T}$ transversion at nucleotide 2418 created an Afl III restriction site.

\section{Results}

\section{Detection of mutations in FGFR-3 gene by SSCP analysis and PCR sequencing}

DNA fragments resulting from exon amplification by PCR were either analyzed by SSCP or directly sequenced. Several abnormal patterns were observed in exon 10 which encodes the transmembrane domain (Fig. 1A). The most common pattern (lane 2) corresponded to the previously reported G/A transition at nucleotide 1138 that occured in achondroplasia patients. It was found in $48 / 50$ cases (Table 2), two other patients had a G/C transversion at the same nucleotide. Both mutations resulted in the G380R substitution while the G375C mutation (14) was not detected in our series.

Another abnormal but distinct pattern of exon 10 (Fig. 1A, lane 5) was also detected in 8/ 26 patients with TD I. Sequencing of the PCR products revealed a recurrent $\mathrm{A} / \mathrm{G}$ transition at nucleotide 1118 which converted tyrosine 373 into cysteine (Table 2). In another TD I patient who presented a normal SSCP pattern of exon 10 , direct sequencing revealed a $\mathrm{G} / \mathrm{T}$ transversion at nucleotide 1108 converting glycine 370 into cysteine. Finally, a relatively uncommon change was observed in exon 10 in one TD I patient and two control DNAs (not shown). Thymidine 1150 was converted into cytosine resulting in the replacement of phenylalanine 384 by leucine, another hydrophobic residue. Indeed, in the chicken FGFR-3 receptor, residue 384 is also a leucine, thus indicating that nucleotide 1150 substitution should be regarded as a neutral polymorphism (frequency 0.04).

SSCP analysis of exon 11 which encodes the TK 1 domain showed two distinct patterns (Fig. 1B) that differed from control. They corresponded to either a $\mathrm{C} / \mathrm{A}$ or a $\mathrm{C} / \mathrm{T}$ tranversion at nucleotide 1659 , both substitutions resulting in the replacement of an asparagine residue by a lysine at position 540 of the protein. This relatively common change was detected in all affected individuals in 9 families but was not found in 9 other families, 3 of them showing clear exclusion of the FGFR-3 locus (15). Among 19 sporadic cases, the N540K mutation was observed in 13 individuals (Table 2). A third abnormal SSCP pattern of exon 11 was detected in one hypochondroplasia patient who did not carry the common mutation. Sequencing disclosed a silent mutation at position 549 in a glycine codon. Further analysis of parental DNA revealed that the asymptomatic father was homozygous for the base change $(\mathrm{G} / \mathrm{T})$ which was detectable by restriction analysis with Apa I. Loss of the Apa I restriction site was also detected in $3 / 40$ control DNAs thus indicating that this polymorphism was not related to the phenotype.

Restriction digestion analysis of PCR products with Bsi HKAI (Fig. 1C) demonstrated that 9 TD I cases out of 26 had a C/T transition at nucleotide 742 which converted arginine 248 into cysteine. In $2 / 26$ cases, a $\mathrm{C} / \mathrm{G}$ transversion occurred at nucleotide 746 (Table 2). Serine 249, 
123456

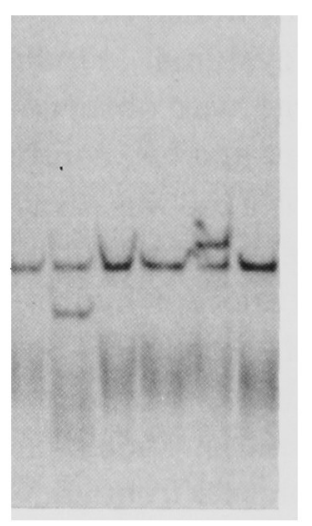

Exon 10 $\begin{array}{lllll}1 & 2 & 3 & 4 & 5\end{array}$

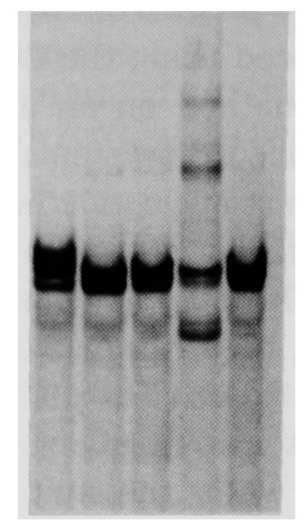

Exon 11

\section{RESTRICTION DIGESTION}

C

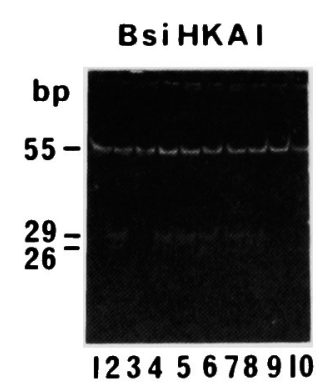

Exon 7

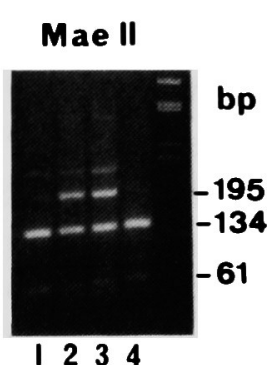

Exon 19

Fig. 1 Detection of FGFR-3 mutations by SSCP and restriction digestion analyses. A: Lanes 1,3,4,6 = control DNAs; lane 2= achondroplasia patient DNA; lane $5=$ TD I patient DNA, B: Lanes $2,3,5=$ control DNAs; lanes 1,4 = hypochondroplasia patients, C: Lanes 1,10= control DNAs; lanes 2-9 = TD I patients (DNAs in lanes 3 and 9 were not digested by Bsi HKAI but by Bso FI which recognized the C746G substitution), D: Lane 1 = control DNA; lanes 2,3,4 = TD I patient DNAs (The patient in lane 4 had a base substitution at nucleotide 2418 which did not abolished the Mae II restriction site). PCR products were restriction digested with Bsi HKAI (C) or Mae II(D). 
Table 2 Summary of FGFR-3 mutations in our series of achondroplasia, hypochondroplasia and TD patients

\begin{tabular}{|c|c|c|c|c|c|c|}
\hline \multirow[t]{2}{*}{ Disease } & \multicolumn{3}{|c|}{ Number of patients } & \multicolumn{3}{|c|}{ FGFR-3 mutations } \\
\hline & Familial & Sporadic & Total & Familial & Sporadic & Total (\%) \\
\hline Achondroplasia & 6 & 44 & 50 & & & \\
\hline G1138A & & & & 6 & 42 & 96 \\
\hline G1138C & & & & 0 & 2 & 4 \\
\hline Hypochondroplasia & 19 & 19 & 38 & & & \\
\hline C1659A & & & & 4 & 9 & 34 \\
\hline C1659G & & & & 4 & 6 & 26 \\
\hline TD I & 0 & 26 & 26 & & & \\
\hline $\mathrm{C} 742 \mathrm{~T}$ & & & & 0 & 9 & 34.6 \\
\hline C746G & & & & 0 & 2 & 7.7 \\
\hline A1118G & & & & 0 & 8 & 30.7 \\
\hline G1108T & & & & 0 & 1 & 3.8 \\
\hline $\mathrm{T} 2416 \mathrm{G}$ & & & & 0 & 2 & 7.7 \\
\hline $\mathrm{T} 2416 \mathrm{~A}$ & & & & 0 & 2 & 7.7 \\
\hline $\mathrm{A} 2418 \mathrm{~T}$ & & & & 0 & 1 & 3.8 \\
\hline
\end{tabular}

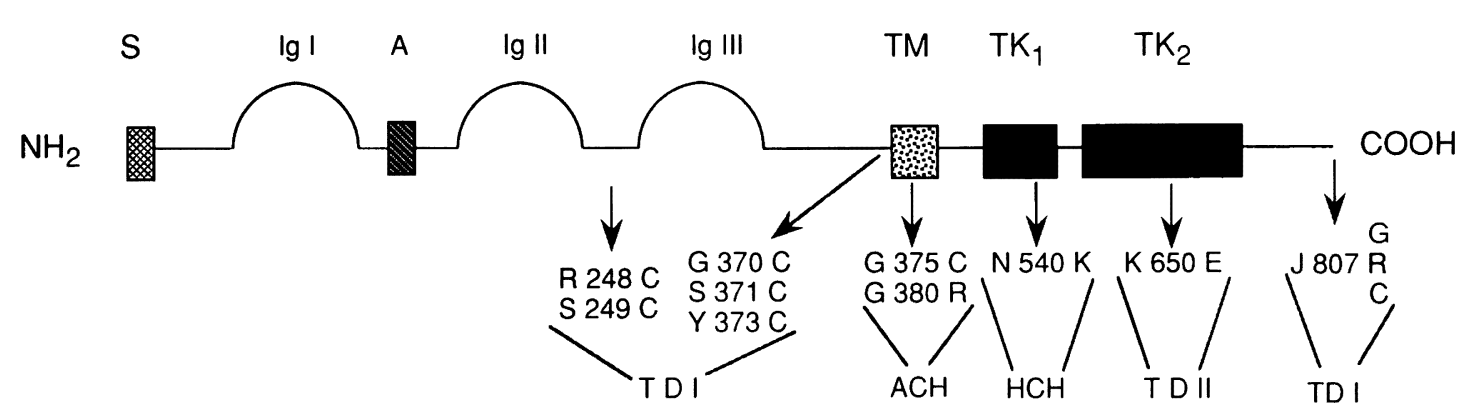

Fig. 2 Schematic structure of human FGFR-3 protein and locations of FGFR-3 mutations causing three skeletal dysplasias: Achondroplasia, Hypochondroplasia, TD (types I and II). TM = transmembrane domain; TK = tyrosine kinase domains ( 1 and 2); Ig = Immunoglobulinlike domains (I, II, III). Arrows show the relative positions of mutations.

like the adjacent arginine 248, was converted into cysteine. Mutations in the stop codon of FGFR3 were identified in $5 / 26$ patients. Substitutions at nucleotide 2416 (T/G or T/A) abolished an Mae II restriction site in 4 cases (Fig. 1D), while the $\mathrm{A} / \mathrm{T}$ transversion at nucleotide 2418 created an AflIII site in one patient. Consistent with the clinical diagnosis of TD 1, none of our patients exhibited the K650E substitution that accounts for TD II but an uncommon polymorphism was detected in intron 14 in two TD cases. Summary of FGFR-3 mutations and their relative location in the protein are presented in Fig. 2.

\section{Radiological and histological data}

Radiographs from TD I foetuses carrying 3 distinct mutations were compared (Fig. 3). Even though femur curvation seemed more obvious in some cases, no direct correlation between position of mutations and radiological features could 


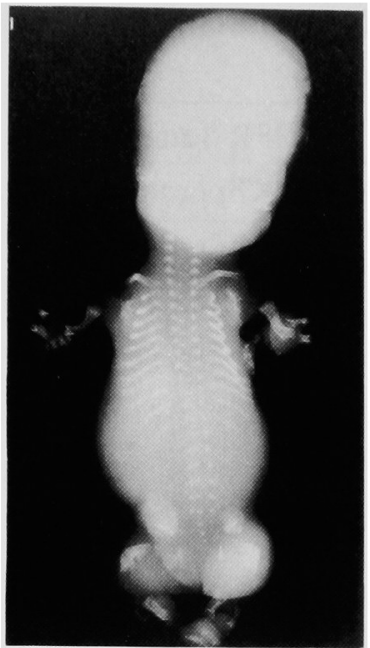

Y373C

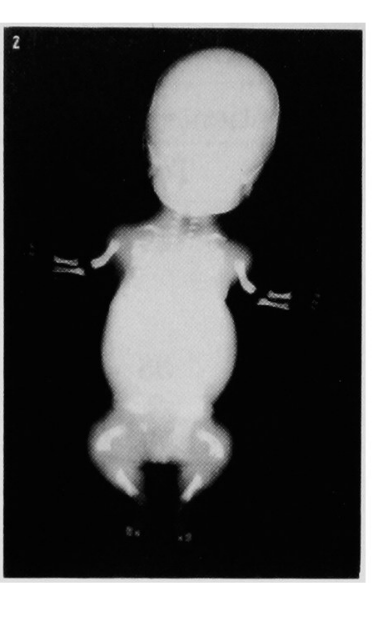

R248C

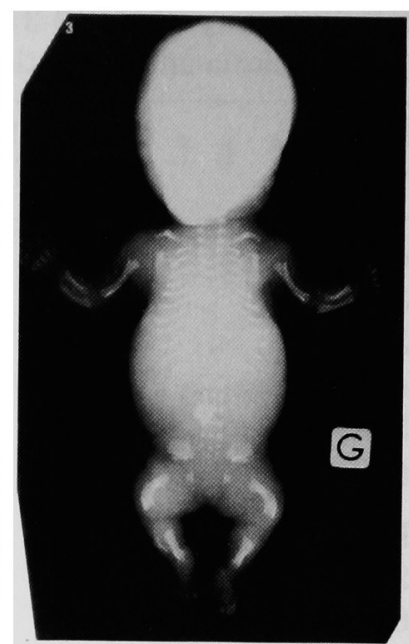

J807G

Fig. 3 Radiographs of three TD1 patients carrying mutations in three different FGFR-3 domains. Foetus 1 (19 weeks); foetus 2 (24 weeks); foetus 3 ( 21 weeks).

be established. Cloverleaf skull was present in only one case but abnormal lobulation of the brain and heterotopia of the temporal lobes was constantly seen.

Histological sections of cartilage samples showed short and disorganized chondrocyte columns in the growth plate, reduced number of hypertrophic cells and lateral overgrowth of bones. Three cases harboring a mutation in the linker region between Ig loops (R248C or S249C) were available for histological analysis. In all of them, a very severe disruption of the growth plate with almost no chondrocyte columns was observed (Fig. 4), suggesting that these mutations might have the most deleterious consequences on cartilage organization. Further cases will be required to verify this assertion.

\section{Discussion}

Fibroblast growth factor receptors (FGFRs) comprise a family of four tyrosine kinase receptors (16) that bind, with varying affinity, fibroblast growth factors (FGFs). This family of nine structurally related heparin-binding polypeptides plays a key role in the growth and differentiation of various cells of mesenchymal and neuroectodermal origin (17). FGFs are also implicated in chemotaxis, angiogenesis, programmed cell death and spatial patterning (18-20).

Recently, mutations in three domains of the FGFR family were associated with several forms of bone dysplasia and craniofacial defects with limb abnormalities $(21,22)$. The first clues of FGFR involvement in chondrodysplasias came from the mapping of achondroplasia to chromosome $4 \mathrm{p} 16(2,3)$. This primary step was followed by the detection of a recurrent mutation in the FGFR-3 gene in achondroplasia patients $(5,6)$. The subsequent identification of FGFR-3 mutations both in TD and hypochondroplasia clearly confirms that these three skeletal disorders belong to a phenotypic chondrodysplasia 'family' (1).

Data presented in Table 2 clearly indicate that both achondroplasia and TD are genetically homogenous conditions. A strikingly different 

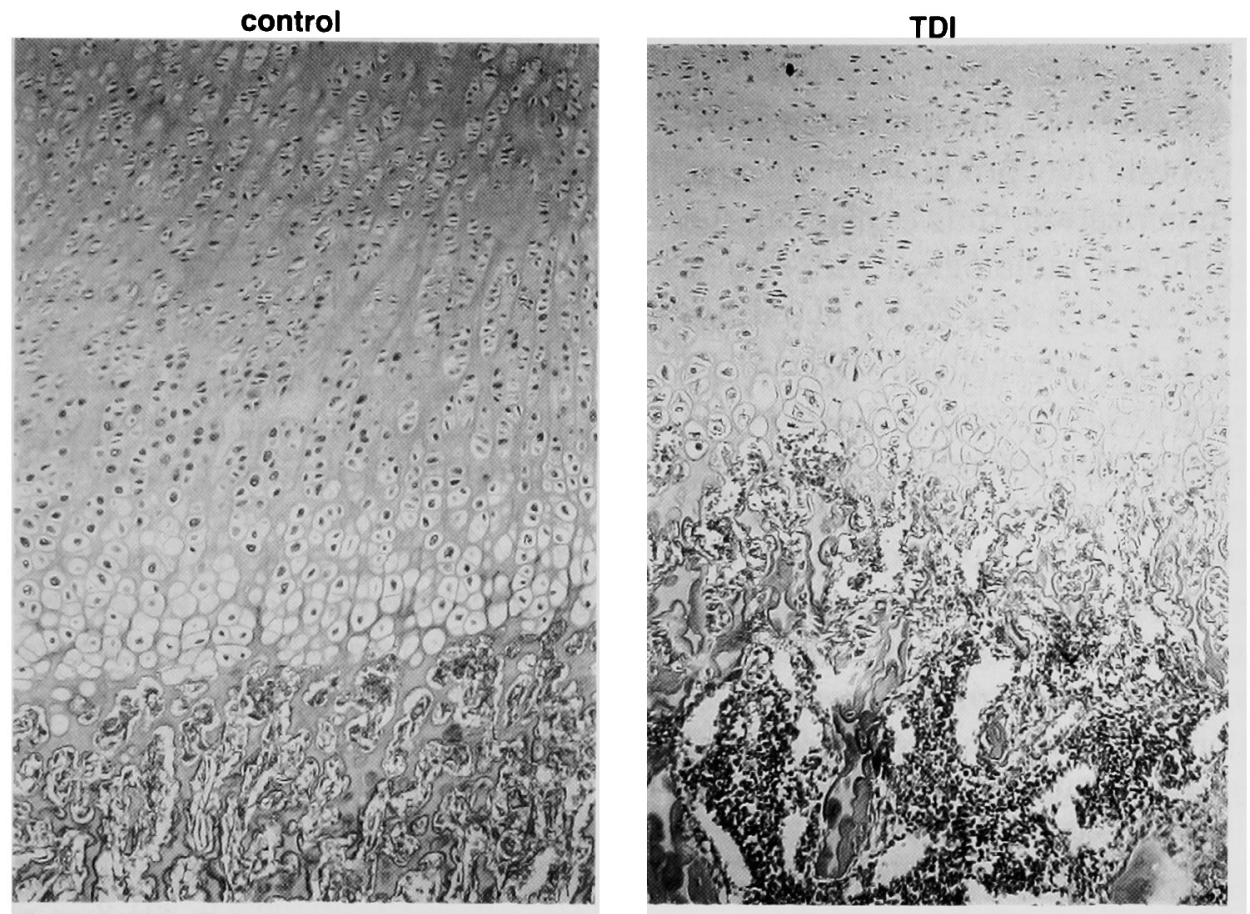

Fig. 4 Histological section of cartilage physeal growth plate from control and TDI case harboring a R248C mutation in the extracellular domain. The lack of chondrocyte columns in TDI is noticeable.

situation was observed with other FGFR related defects. Hence, in some types of craniosynostoses (Crouzon and Pfeiffer syndromes), either mutations in the FGFR-2 or the FGFR-1 receptors resulted in the same phenotype $(23,24)$.

The mechanisms leading to skeletal growth retardation of variable severity in achondroplasia, hypochondroplasia or TD are far from being understood, especially as mutations in different critical domains of the receptor have been identified. Binding of a FGF ligand to its receptor is known to require the presence of a low affinity heparan sulfate proteoglycan co-receptor $(25,26)$ to elicit receptor dimerization and the subsequent tyrosine phosphorylation. The activated receptor can phosphorylate cytoplasmic proteins with SH2 (Src Homology 2) domains and a series of serine/threonine protein kinases (MAPK, MAP$\mathrm{KK}, \mathrm{MAPKKK}$ ) leading to the activation of intranuclear transcription factors (27).
The introduction of a hydrophilic residue in a highly hydrophobic receptor domain, like in achondroplasia is expected to disrupt the $\alpha$ helical structure of the transmembrane portion and could interfere with signal transduction elicited by ligand binding. Whether such an alteration would reduce or accelerate chondrocyte differentiation and proliferation is not yet elucidated. Interestingly, FGFR-3 mutations that occurred in the extracellular receptor domain of TD I patients created new unpaired cysteine residues. We suggest that disulfide bonding between two mutant monomers could induce receptor dimerization independently of the ligand. Such an autonomous receptor activation has been observed with other tyrosine-kinase receptors including colony stimulating factor 1 (CSF-1), epidermal growth factor (EGFR) and RET oncogene (28-30). Whether stop codon mutations which are expected to give rise to an elongated 
receptor by 141 amino-acids also induce receptor activation, is questionable. Indeed, the presence of a cysteine-rich domain in the putative additional peptide may produce constitutive receptor homodimerization, thus explaining the absence of significant radiological differences between patients carrying stop codon mutations or substitutions in the extracellular domain. Of particular interest was the recent demonstration that Fgfr-3 deficient mice generated by gene targeting displayed lengthening of the femurs. The resulting expansion of the hypertrophic growth plate cartilage as opposed to the narrow zone of hypertrophic chondrocytes seen in cartilage of TD I patients, irrespective of the position of FGFR-3 mutations, supports the hypothesis that FGFR-3 is a negative regulator of skeletal growth (31).

Further experiments using both transgenic animals and transfected cells are required to establish if missense mutations in FGFR-3 induce loss or gain of function of the receptor.

\section{Acknowledgements}

We thank members of the French chondrodysplasia network for providing samples. This work was supported by an INSERM grant and by the European Concerted Action on chondrodysplasias (Biomed 1, Contract BMH1-CT93-1316).

\section{References}

1. Spranger J. Bone dysplasia families. Pathol Immunopathol Res 1988; 7: 76-80.

2. Le Merrer M, Rousseau F, Legeai-Mallet L, Landais JC, Pelet A, Bonaventure J, et al. A gene for achondroplasia-hypochondroplasia maps to chromosome 4p. Nature Genet 1994; 6: 318-21.

3. Velinov M, Slaugenhaupt SA, Stoilov I, Scott Jr CI, Gusella JF, Tsipouras P. The gene for achondroplasia maps to the telomeric region of chromosome 4p. Nature Genet 1994; 6: 314-7.

4 Peters K, Ornitz D, Werner S, Williams L. Unique expression pattern of the FGF receptor-3 during mouse organogenesis. Dev Biol 1993; 155: 42330.

5. Shiang R, Thompson LM, Zhu Y-Z, Church DM, Fielder TJ, Bocian M, et al. Mutations in the transmembrane domain of FGFR-3 cause the most common genetic form of dwarfism, achondroplasia. Cell 1994; 78: 335-42.

6. Rousseau F, Bonaventure J, Legeai-Mallet L, Pelet A, Rozet J-M, Maroteaux $\mathrm{P}$, et al. Mutations in the gene encoding fibroblast growth factor receptor-3 in achondroplasia. Nature 1994; 371 : 252-4.

7. Bellus G, Hefferon TW, Ortiz de Luna RI, Hecht JT, Horton WA, et al. Achondroplasia is defined by recurrent G380R mutations of FGFR-3. Am J Hum Genet 1995; 56: 368-73.

8. Tavormina PL, Shiang R, Thompson LM, Zhu YZ, Wilkin DJ, Lachman RS, et al. Thanatophoric dysplasia (types I and II) caused by distinct mutations in fibroblast growth factor receptor 3. Nature Genet 1995; 9: 321-8.

9. Rousseau F, Saugier P, Le Merrer M, Munnich A, Delezoide A-L, Maroteaux $\mathrm{P}$, et al. Stop codon FGFR-3 mutations in thanatophoric dysplasia type I. Nature Genet 1995; 10: 11-2.

10. Bellus GA, McIntosh I, Smith AE, Aylsworth AS, Kaitila I, Horton WA, et al. A recurrent mutation in the tyrosine kinase domain of fibroblast growth factor receptor 3 causes hypochondroplasia. Nature Genet. 1995; 10: 357-9.

11. Prinos P, Costa T, Sommer A, Kilpatrick MW, Tsipouras P. A common FGFR-3 mutation in hypochondroplasia. Hum Mol Genet 1995; 4: 2097-101.

12. Perez-Castro AV, Wilson J, Altherr MR. Genomic organization of the mouse fibroblast growth factor receptor 3 (Fgfr3) gene. Genomics 1995; 30: 157-62.

13. Tavormina PL, Rimoin DL, Cohn DH, Zhu Y-Z, Shiang R, Wasmuth JJ. Another mutation that results in the substitution of an unpaired cysteine residue in the extracellular domain of FGFR3 in thanatophoric dwarfism type I. Hum Mol Genet 1995; 4: 2175-7.

14. Superti-Furga A, Eich G, Bucher HU, Wisser J, Giedon A, Gitzelmann R, et al. A glycine 375 to cysteine substitution in the transmembrane do- 
main of the fibroblast growth factor receptor-3 Eur J Pediat 1995; 154: 215-9.

15. Rousseau F, Bonaventure J, Hayden MR, Munnich A, Le Merrer M. Not all hypochondroplasia families are linked to chromosome 4p16.3. Am J Hum Genet 1994; 55: A102.

16. Johnson DE, Williams LT. Structural and functional diversity in the FGF receptor multigene family. Adv Cancer Res 1993; 60: 1-41.

17. Givol D, Yayon A. Complexity of FGF receptors: genetic basis for structural diversity and functional specificity. FASEB J. 1992; 6: 3362-9.

18. Burgess WH, Maciag $T$. The heparin-binding (fibroblast) growth factor family of proteins. Annu Rev Biochem 1989; 58: 575-606.

19. Basilico C, Moscatelli D. The FGF family of growth factors and oncogenes. Adv Cancer Res 1992; 59: 115-65.

20. Laufer E, Nelson CE, Johnson RL, Morgan BA, Tabin C. Sonic hedgehog and FGF-4 act through a signaling cascade and feedback loop to integrate growth and patterning of the developing bud. Cell 1994; 79: 993-1003.

21. Park W-J, Bellus G, Jabs EW. Mutations in fibroblast growth factor receptors: phenotypic consequences during eukaryotic development. Am J Hum Genet 1995; 57: 748-54.

22. Muenke M, Schell U. Fibroblast-growth factor receptor mutations in human skeletal disorders. TIG 1995; 11: 308-13.

23. Rutland P, Puleyn LJ, Reardon W, Baraitser M, Hayward R, Jones B, et al. Identical mutations in the FGFR 2 gene cause both Pfeiffer and Crouzon phenotypes. Nature Genet 1995; 9: 173-6.

24. Schell U, Hehr A, Feldman GJ, Robin NH, Zackai $\mathrm{EH}$, de Die-Smulders, et al. Mutations in FGFR1 and FGFR2 cause familial and sporadic Pfeiffer syndrome. Hum Mol Genet 1995; 4: 323-8.

25. Spivak-Kroizman T, Lemmon MA, Dikic I, Ladbury JE, Pinchasi $\mathrm{D}$, Huang $\mathrm{J}$, et al. Heparin-induced oligomerization of FGF molecules is responsible for receptor dimerization, activation and cell proliferation. Cell 1994; 79: 1015-24.

26. Aviezer D, Hecht D, Safran M, Eisinger M, David G, Yayon A. Perlecan, basal lamina proteoglycan, promotes basic fibroblast growth factor-receptor binding, mitogenesis and angiogenesis. Cell 1994; 79: 1005-13.

27. Marshall CJ. Specificity of receptor tyrosine kinase signaling: transient versus sustained extracellular signal-regulated kinase activation. Cell 1995; 80: 179-85.

28. Roussell MF, Downing JR, Sherr CJ. Transforming activities of human CSF-1 receptors with different point mutations at codon 301 in their extracellular domain. Oncogene 1990; 5: 25-30.

29. Sorokin A, Lemmon MA, Ullrich A, Schlessinger J. Stabilization of an active dimeric form of the epidermal growth factor by introduction of an inter-receptor disulfide bond. J Biol Chem 1994; 269: 9752-9.

30. Santoro M, Carlomagno F, Romano A, Bottaro DP, Dothan NA, Grieco M, et al. Activation of $\mathrm{RET}$ as a dominant transforming gene by germline mutations of MEN2A and MEN2B. Science 1995; 267: 381-3.

31. Deng C, Wynshaw-Boris, Kuo A, Leder P. Fibroblast growth factor receptor 3 is a negative regulator of bone growth and development. Am J Hum Genet 1995; 57: A54. 